๑ The Author(s), 2018. Published by Cambridge University Press on behalf of the Society for Industrial and Organizational Psychology. This is an Open Access article, distributed under the terms of the Creative Commons Attribution licence (http://creativecommons.org/licenses/by/4.0/), which permits unrestricted re-use, distribution, and reproduction in any medium, provided the original work is properly cited.

\title{
Beyond Managing Research Partnerships: Partnered Research as an Integrated Methodological Approach
}

\author{
Silvia Bonaccio \\ University of Ottawa \\ Catherine E. Connelly \\ McMaster University \\ Sandra L. Fisher \\ Clarkson University \\ Ian R. Gellatly \\ University of Alberta \\ Monique A. M. Gignac and Arif Jetha \\ Institute for Work \& Health \\ University of Toronto
}

Lapierre et al. (2018) provide a compelling set of reasons why conducting research in organizational settings should include investing time and energy to foster and promote enhanced relationships with organizational stakeholders. We agree that managing research partnerships carefully is paramount to creating the conditions necessary to implement rigorous methodology and collect the data needed to test theory-based hypotheses. However, we believe that Lapierre et al.'s argument should be taken further.

We propose that, to further enhance applied research, partnerships, and integrating partner perspectives could be integral throughout the entire research process. An integrated partnered research approach has been fruitfully implemented in many other disciplines, particularly in the health sciences, including public health, rehabilitation science, kinesiology, and community medicine, as well as in some areas of psychology such as community psychology. This approach potentially offers similar benefit to researchers in industrial-organizational psychology and organizational behavior (IOOB). Indeed, partnered research, when integrated throughout a project, can

Silvia Bonaccio, Telfer School of Management, University of Ottawa; Catherine E. Connelly, DeGroote School of Business, McMaster University; Sandra L. Fisher, Reh School of Business, Clarkson University; Ian R. Gellatly, Alberta School of Business, Strategic Management and Organization, University of Alberta; Monique A. M. Gignac, Institute for Work \& Health, and Dalla Lana School of Public Health, University of Toronto; Arif Jetha, Institute for Work \& Health, and Dalla Lana School of Public Health, University of Toronto.

The authors wish to acknowledge a grant from the Social Sciences and Humanities Research Council of Canada (\#895-2013-1021).

Correspondence concerning this article should be addressed to Silvia Bonaccio, Telfer School of Management, University of Ottawa, Ottawa, Ontario, Canada. E-mail: bonaccio@telfer.uottawa.ca 
be an invaluable source of research questions, insights, information/data, analytics/interpretation, a nexus for interdisciplinary perspectives, and vehicle for knowledge transfer. In short, research partnerships offer more than simply creating the conditions for data collection. Integrating research partnerships into a study's methodology can generate new knowledge and, perhaps most important, facilitate dissemination and bring about meaningful change (Kidd et al., 2018; Nicolaidis et al., 2011). To this end, an integrated, partnered research offers solutions to several of the challenges identified by Lapierre et al. across their four broad objectives (i.e., initiating a relationship, deciding early whether to pursue or end it, keeping the partner engaged, and keeping the relationship alive post-data collection). By adopting a partnered research approach, many of these challenges represent opportunities rather than liabilities. Below, we share examples of partnered research from our work studying the lived experiences of workers with disabilities.

\section{What Is Partnered Research?}

Partnered research is the meaningful integration of academic and nonacademic, nonresearcher stakeholders in all elements of the research process, from the creation and generation of research questions to the dissemination and application of research results (Cashman et al., 2008; Ross et al., 2010; Van Eerd \& Saunders, 2017). Together, "researchers and research users work together to shape the research process by collaborating to determine the research questions, deciding on the methodology, being involved in data collection and tools development, interpreting the findings, and helping disseminate the research results" (Canadian Institutes for Health Research [CIHR], 2016, Integrated KT). The aim of such an approach is to "produce research findings that are more likely to be relevant to and used by the end users." Oftentimes, "the goal is for community partners to have equal authority and responsibility with the academic research team. This is not to say that each partner has an equal role at each stage of the process. Rather, ... partners negotiate roles and responsibilities depending on the different expertise brought by members of the community and of the academic research team as well as the different goals and motivation of each party" (Ross et al., 2010, p. 19). We discuss these ideas in the context of IOOB below.

\section{Who Are the Nonresearcher Stakeholders?}

In IOOB, we typically think of the research end users, that is our nonresearcher stakeholders, as organizations and their employees. We draw on organizational theories to generate testable hypotheses that will generate knowledge aimed at having a positive impact on, or otherwise influence, organizational actors (members of the C-suite, middle managers, employees) in terms of important outcomes (attitudes, behaviors). These stakeholders 
are also relevant in partnered research. However, partnered research often makes a point of starting with the individuals or groups being studied as key stakeholders. This is especially the case when these individuals have been historically marginalized (Kidd et al., 2018). Thus, when studying the experiences of an equity-seeking group like workers with disabilities, it is critical to include representatives of these workers as nonresearcher stakeholders rather than only giving voice to the top managers and HR staff from the partner organizations.

Another unique feature of partnered research is the creation of knowledge that will be useful for other key research end-users, such as relevant community groups (e.g., advocacy groups) as well as policy makers. Thus, in addition to assisting organizational partners in answering important questions, partnered research provides added societal benefits of evidence-based policy and advocacy. It also helps to ensure that potential challenges in implementing evidence across diverse organizations are recognized early. In this way, research findings have a greater chance to be applicable to a wide range of workplaces and worker needs. This is a key opportunity for IOOB given the ongoing SIOP efforts to advocate for I-O science and practice in federal public policy (SIOP, 2018).

In selecting nonresearcher stakeholder(s) when initiating the relationships phase (Objective I), Lapierre et al. (2018) rightly focus on the practicalities of relationship building (identifying data collection facilitators, establishing contacts, engaging with senior leaders). However, an integrated, partnered approach also encourages researchers to be strategic and embrace stakeholder perspectives that are diverse and that even may be traditionally thought to be in opposition to one another (e.g., management and organized labor) (Van Eerd \& Saunders, 2017). Working with a range of stakeholders to identify both their varied and shared interests takes considerable time and effort and should be undertaken early in the life course of a study. Having recognized and included a range of perspectives into the research questions enables the study team to see unique facets of a research problem, helps the team to bond and agree on the value of an evidence-based approach, and is often the hallmark of a fruitful and long-term partnership. For example, by including disability managers, HR personnel, union representatives, and workers in some of our research related to accommodating workers with disabilities, we (and our partners) became more aware of the complexities of disability prevention and the critical nature of the timing of involvement of different groups in accommodation planning.

\section{On Research Questions, Design, and Data Collection}

In partnered research, nonresearcher stakeholders are invited to collaborate closely with the researchers to conceptualize the research aims and 
questions. The key to success as the stakeholder engagement moves toward a true integrated partnership is two-way continual dialogue between the researchers and the nonacademic stakeholders (Van Eerd \& Saunders, 2017). In fact, the research question that gives life to the research program often comes from the partner. It is this practical question that then motivates the academic researchers in partnership with the stakeholders to identify relevant research theories and hypotheses that can help illuminate the answer to the stakeholder's question.

Once research questions are determined, the partner further collaborates with the academic team on study implementation, which extends to planning the study methods. The collaboration on planning the methods ensures that concerns raised by Lapierre et al. (2018) in Objective II, such as "Does the organization want to alter the research materials?" (p. 565), are addressed. This does not mean that researchers are not primarily responsible for ensuring the scientific soundness of a study (Ross et al., 2010). Instead, researchers facilitate meaningful conversations with those who have less experience with the scientific process to ensure that partners have a lay understanding of issues like sampling and an appreciation for the necessity of methodological rigor (Nicolaidis et al., 2011). Our experience in working directly with stakeholders is that they prefer to leave methodological decisions with their academic research partners. Yet, their input on methods is often highly desirable and valuable as it often pertains to whether recruitment targets are feasible, whether potential respondents will be willing to participate in the research, and whether the findings from the data will address key stakeholder concerns

As a way to help curb concerns about methodological integrity following the involvement of nonresearcher stakeholders, some institutions host research methods workshops aimed at lay people and publish short papers to help nonresearchers become familiar with research terminology (see e.g., "What researchers mean by", IWH, n.d.). The latter is an activity that SIOP members often engage in as well (see, e.g., the "Lost in Translation" TIP columns). Granting agencies like the CIHR also have reached out to individuals living with health conditions and disabilities as Research Ambassadors. These individuals work with the granting agency and researchers to receive research education and to provide their input on ways to better involve and educate stakeholders about research.

\section{On Data Interpretation, Use, and Dissemination}

Ensuring that academics enlist the help of nonacademic partners in interpreting the study findings, an important element of partnered research, responds to the concerns raised by Lapierre et al. (2018) in Objective III ("How to maintain the engagement and commitment" of key people, p. 569). In 
the context of public health research, Cashman et al. (2008) discuss how nonacademic stakeholders can be successfully enlisted to help interpret research findings. Importantly, they show that this involvement works even in quantitative, survey-based research. This involvement echoes the phrase often used by disability advocacy groups "nothing about us without us," indicating that partners may be in the best position to elucidate what the findings mean given their context.

An additional advantage of partnered research is the attention to knowledge transfer and exchange (KTE). By working closely with the community partners, academics are afforded the opportunity to learn what KTE materials are most relevant and useful, and therefore, have a greater opportunity for applied impact. Taking a partnered research approach will increase the likelihood that findings are relevant and utilized by end-users (Kidd, et al., 2018; Van Eerd \& Saunders, 2017). Thus, instead of viewing deliverables as a bargaining tool ("Deliverables ... could be promised to organizations as a way of securing their support," Lapierre et al., 2018, p. 561, Objective I), the partnered approach encourages a lengthy and specific discussion on developing strategies for the appropriate dissemination of information that are meaningful to the partners. This can take the form of presentations, videos, newsletters, focus groups, training, or other initiatives. Thus, these KTE outcomes go beyond the important-though superficial-report produced for the organization after data collection is complete. As a byproduct of the focus on KTE that accompanies partnered research, some of the concerns discussed in Objective IV ("Ensuring the organization feels its involvement ... was worthwhile," Lapierre et al., 2018, p. 571) are also addressed.

When viewed through the lens of partnered research other issues identified by Lapierre et al. represent opportunities rather than risks. Questions, for instance, that pertain to the ownership of the data, access rights, the right to publish/present results (Objective II) take on different tone. In some cases, "both have legitimate claims as both partners will have been integral to data collection and have a stake in data analysis. For this reason, speaking of ownership is likely to be a dead end" (Ross et al., 2010, p. 28). Instead, the focus could be on mutually beneficial and respectful dissemination of research findings, in each case, respecting the mutual obligations of the parties.

\section{Partnered Research in Action: An Illustration}

In this section we consider how the partnered research methodology has impacted our work on the lived experiences of people with disabilities.

\section{Problem Conceptualization}

During an early "getting to know us" meeting between us and a community organization, one of its members made a passing comment about wishing 
they could gather more systematic information about how they provided services to their clients. After looking at the IOOB and other relevant literatures, our research team identified an opportunity for empirical work in an area that was heretofore unexplored.

\section{Methodological Rigor}

Because our focal population (i.e., people with disabilities) may have difficulty participating in research if it is not in an accessible format, we have found that our partners are especially helpful in identifying potential problems and providing appropriate solutions. For example, questions may need to be worded carefully (e.g., to use language preferred by respondents) or an alternative format may have to be offered (e.g., surveys may be completed orally) to be accessible to intended respondents.

\section{Interpretation and Dissemination}

Because our community partners bring important lived experience to our collaborations, analyses of our data have been enhanced. Community partners have asked questions relevant to their diverse needs and that, when addressed through research data, better highlight employment challenges and successes among those living with a disability (e.g., finding work, sustaining employment, returning to work). We have also benefited from community partners acting as champions of our studies. This has helped us refine our study messages and reach out to relevant groups to disseminate our findings beyond traditional academic routes (i.e., peer-reviewed publications). Examples include presenting findings to human resource professionals and disability managers at their professional association meetings.

\section{Concluding Thoughts}

In sum, partnered research is alive and well in fields other than IOOB. In fields like medicine, where the stakes are typically thought to be even higher than they are in organizational research and the time pressure is ever present, partnered research has been shown to ensure the "relevance and responsiveness" (Selby \& Slutsky, 2014, ${ }^{1}$ p. S815) of research questions and design. That said, partnered research represents a significant investment of time and effort, and requires a longer term orientation than is normally the case in IOOB research. As the field moves toward more impactful work on stakeholders and their communities, approaches like partnered research should be increasingly more prevalent. One only has to look at how other fields have grappled with issues of collaboration and partnership in the research

1 See also other related articles in this special issue at https://www.ncbi.nlm.nih.gov/pmc/ issues/245501/. 
enterprise. The case for cross-disciplinary methodological pollination has been made in the pages of this same journal on other occasions (e.g., Guzzo, Fink, King, Tonidandel, \& Landis, 2015; Pratt \& Bonaccio, 2016). Much innovation in IOOB is to be gained by implementing methods that other fields master. Partnered research is "'research-plus' that is both methodologically rigorous and that makes unique contributions not possible using other means" (O’Toole, Aaron, Chin, Horowitz, \& Tyson, 2003, p. 592).

\section{References}

Canadian Institutes of Health Research (CIHR). (2016). About knowledge translation. Retrieved from http://www.cihr-irsc.gc.ca/e/29418.html

Cashman, S. B., Adeky, S., Allen III, A. J., Corburn, J., Israel, B. A., Montaño, J., Rafaelito, A., Rhodes, S.D., Swanston, S., Wallerstein, N., \& Eng, E. (2008). The power and the promise: Working with communities to analyze data, interpret findings, and get to outcomes. American Journal of Public Health, 98(8), 1407-1417. doi:10.2105/AJPH.2007.113571

Guzzo, R., Fink, A., King, E., Tonidandel, S., \& Landis, R. (2015). Big data recommendations for industrial-organizational psychology. Industrial and Organizational Psychology, 8(4), 491-508. doi:10.1017/iop. 2015.40

Institute for Work and Health. (n.d.). What researchers mean by. Retrieved from http://www.iwh.on. $\mathrm{ca} /$ what-researchers-mean-by

Kidd, S., Davidson, L., Frederick, T., \& Kral, M. J. (2018). Reflecting on participatory, action-oriented research methods in community psychology: Progress, problems, and paths forward. American Journal of Community Psychology, 61(1-2), 76-87. doi:10.1002/ajcp.12214

Lapierre, L. M., Matthews, R. A., Eby, L. T., Truxillo, D. M., Johnson, R.E., \& Major, D. A. (2018). Recommended practices for academics to initiate and manage research partnerships. Industrial and Organizational Psychology: Perspectives on Science and Practice, 11(4), 543-581.

Nicolaidis, C., Raymaker, D., McDonald, K., Dern, S., Ashkenazy, E., Boisclair, C., Robertson, C., \& Baggs, A. (2011). Collaboration strategies in nontraditional community-based participatory research partnerships: Lessons from an academic-community partnership with autistic selfadvocates. Progress in Community Health Partnerships, 5(2), 143. doi:10.1353/cpr.2011.0022

O’Toole, T.P., Aaron, K. F., Chin, M. H., Horowitz, C., \& Tyson, F. (2003). Community-based participatory research: Opportunities, challenges, and the need for a common language. Journal of General Internal Medicine, 18(7), 592-594. doi:10.1046/j.1525-1497.2003.30416.x

Pratt, M. G., \& Bonaccio, S. (2016). Qualitative research in I-O psychology: Maps, myths, and moving forward. Industrial and Organizational Psychology, 9(4), 693-715. doi:10.1017/iop.2016.92

Ross, L. F., Loup, A., Nelson, R. M., Botkin, J. R., Kost, R., Smith Jr., G. R., \& Gehlert, S. (2010). The challenges of collaboration for academic and community partners in a research partnership: Points to consider. Journal of Empirical Research on Human Research Ethics, 5(1), 19-31. doi:10.1525/jer.2010.5.1.19

Selby, J. V., \& Slutsky, J.R. (2014). Practicing partnered research. Journal of General Internal Medicine, 29(Suppl 4), S814-816. doi:10.1007/s11606-014-3046-Z

SIOP. (2018). Government relations. Retrieved from http://www.siop.org/Advocacy/

Van Eerd, D., \& Saunders, R. (2017). Integrated knowledge transfer and exchange: An organizational approach for stakeholder engagement and communications. Scholarly and Research Communication, 8(1). http://doi.org/10.22230/src.2017v8n1a274 